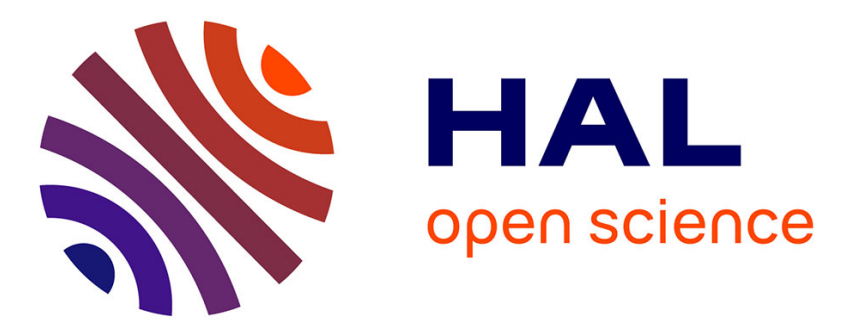

\title{
Determination of bixin and norbixin in meat using liquid chromatography and photodiode array detection.
}

Herlinde Noppe, Sonja Abuin Martinez, Karolien Verheyden, Joris van Loco, R. Companyo Beltran, Hubert de Brabander

\section{- To cite this version:}

Herlinde Noppe, Sonja Abuin Martinez, Karolien Verheyden, Joris van Loco, R. Companyo Beltran, et al.. Determination of bixin and norbixin in meat using liquid chromatography and photodiode array detection.. Food Additives and Contaminants, 2009, 26 (01), pp.17-24. 10.1080/02652030802322564 . hal-00577300

\author{
HAL Id: hal-00577300 \\ https://hal.science/hal-00577300
}

Submitted on 17 Mar 2011

HAL is a multi-disciplinary open access archive for the deposit and dissemination of scientific research documents, whether they are published or not. The documents may come from teaching and research institutions in France or abroad, or from public or private research centers.
L'archive ouverte pluridisciplinaire HAL, est destinée au dépôt et à la diffusion de documents scientifiques de niveau recherche, publiés ou non, émanant des établissements d'enseignement et de recherche français ou étrangers, des laboratoires publics ou privés. 


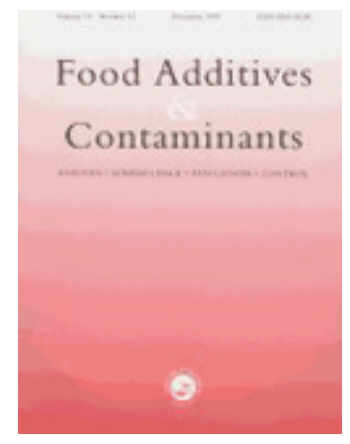

\section{Determination of bixin and norbixin in meat using liquid chromatography and photodiode array detection.}

\begin{tabular}{|r|l|}
\hline Journal: & Food Additives and Contaminants \\
\hline Manuscript ID: & TFAC-2008-045.R3 \\
\hline Manuscript Type: & Original Research Paper \\
\hline Author: & 17-Jun-2008 \\
\hline Complete List of Authors: & $\begin{array}{l}\text { Noppe, Herlinde; Ghent University, Faculty of Veterinary Medicines, } \\
\text { Veterinary Public Health and Food Safety } \\
\text { Martinez, Sonja; Barcelona University, Faculty of Chemistry, } \\
\text { Analytical Chemistry } \\
\text { Verheyden, Karolien; Ghent University, Faculty of Veterinary } \\
\text { Medicines, Veterinary Public Health and Food Safety } \\
\text { Van Loco, Joris; Institute of Public Health, Pharmaco-bromatology, } \\
\text { Food Section } \\
\text { Beltran, R.; Barcelona University, Faculty of Chemistry, Analytical } \\
\text { Chemistry } \\
\text { De Brabander, Hubert; Ghent University, Veterinary Public Health } \\
\text { and Food Safety }\end{array}$ \\
\hline Methods/Techniques: & Chromatography - LC/MS, In-house validation, Method validation \\
\hline Additives/Contaminants: & Residues \\
\hline Food Types: & Meat \\
\hline &
\end{tabular}

\section{SCHOLARONE} Manuscripts 


\section{Determination of bixin and norbixin in meat using liquid chromatography}

2 and photodiode array detection

3

$4 \quad{ }^{1} \mathrm{H}$. NOPPE, ${ }^{2} \mathrm{~S}$. ABUÍN MARTINEZ, ${ }^{1} \mathrm{~K}$. VERHEYDEN, ${ }^{3} \mathrm{~J}$. VAN LOCO, ${ }^{2} \mathrm{R}$.

5 COMPANYÓ BELTRAN, ${ }^{1}$ H.F. DE BRABANDER

6

$7 \quad{ }^{1}$ Ghent University, Faculty of Veterinary Medicine, Research group of Veterinary Public Health and

8 Zoonoses, Laboratory of Chemical Analysis, Salisburylaan 133, B-9820 Merelbeke, Belgium

$9{ }^{2}$ Barcelona University, Faculty of Chemistry, Department of Analytical Chemistry, Avinguda

10 Diagonal, 647, E-08028 Barcelona, Spain

$11{ }^{3}$ Institute of Public Health, Department of Pharmaco-bromatology, Food Section, J. Wytsmanstraat, 12 B-1050 Brussels, Belgium

15 Correspondence: H.F. De Brabander. E-mail: Hubert.DeBrabander@UGent.be 


\begin{abstract}
16 Abstract
17 In this study, the development of an analytical method that enables routine analysis of the dyes

18 annatto, bixin and norbixin in meat tissue is described. Liquid solid extraction was carried out using

19 acetonitrile. Analysis was by HPLC with photodiode array detection using 2 fixed wavelengths (458

20 and $486 \mathrm{~nm}$ ). Additionally, the possibilities of ion trap mass spectrometry (MS) were assessed.

21 Method performance characteristics according to Commission Decision 2002/657/EC were

22 determined, with recoveries between 99 and $102 \%$ and calibration curves being linear in the 0.5 to 10

$23 \mathrm{mg} \mathrm{kg}^{-1}$ range. The limit of quantification was $0.5 \mathrm{mg} \mathrm{kg}^{-1}$.

24
\end{abstract}

25 Keywords: annatto, bixin, norbixin, meat, liquid chromatography, photodiode array 26 
As colour is often a key consumer perception for food preference and acceptability, natural and synthetic colorants have extensively been used to colour food, drugs and cosmetics (Bittencourt et al., 2005). Due to restrictions on the use of these synthetic colorants, there has been a growing interest from the food industry to use natural colorants.

Annatto extracts (E160b) are orange/red natural carotenoid dyes obtained from the seeds of the tropical shrub Bixa Orellana L. and are nowadays widely used by the food industry to colour many food products including high fat dairy products such as butter and cheese, cereals, snack foods, seasonings, creamers, ice creams, flour, sugar confectionary, soft drinks and fish (Lancaster and 38 Lawrence, 1996, Scotter et al., 1994 \& 1995, 2002). The principal coloring component of annatto 39 seeds is cis-bixin, which is soluble in most polar organic solvents to which it imparts an orange colour, 40 but which is largely insoluble in vegetable oil (Scotter et al., $1994 \&$ \& 1995, 2002). Cis-bixin is the 41 monomethyl ester of cis-norbixin (figure 1) (Scotter et al., 1994). The amounts of the active pigments 42 bixin and norbixin in annatto can vary from less than $1 \%$ to over $85 \%$, dependent on the type of 43 annatto extract e.g. water, vegetable oil, solvent (Tennant and O'Callaghan, 2005, WHO, 2007) and 44 are affected by degradation agents, such as light, temperature, air, anti- and pro-oxidants and $\mathrm{pH}$ 45 (Najar et al., 1988). The degradation products are of commercial significance, since by controlling the 46 degree of the degradation, the orange/red to yellow colour balance of an Annatto formulation can be adjusted (Scotter, 1995).

Notwithstanding the large use of annatto pigments as food colorants, practically no information exists about their toxicological properties for animals and humans. Toxicity was mostly determined in 51 animals using commercial annatto preparations containing undetermined amounts of bixin and 52 norbixin (Engelberth-Holm and Iversen, 1955, Van Esch et al., 1959). Toxicological data about 53 annatto pigments are limited, possibly because food additives derived from natural sources have been 54 given exemption from certification (Hallagan et al., 1995). The Joint FAO/WHO Expert Committee on 
55 Food Additives (JECFA) estimated the ADI for annatto as $0-2.5 \mathrm{mg} / \mathrm{kg}$ body weight / day (for a 56 preparation containing 2,6\% cartenoids expressed as bixin) and $0-0.065 \mathrm{mg} / \mathrm{kg}$ body weight/day 57 expressed as the pure pigment (WHO, 2007).

In recent years, there has been a growing concern about the presence of these compounds in edible 60 matrices of animal origin. Consequently the use of colorants in foodstuffs has been regulated by the 61 European Union (Council Directive EC/94/36). Depending on the colorant (e.g. annatto or E160b) and 62 the matrix (e.g. fish tissue and dairy products) Maximum Residue Levels (MRLs) have been proposed. 63 Annatto extracts are listed amongst those colorants that may be used separately or in combination in 64 certain foods up to the maximum levels specified (on a ready-for-consumption basis) (Scotter et al., 65 2002). Other edible matrices, e.g. molluscs, crustaceans, meat tissue, poultry and game, as well as 66 their preparations may not contain added annatto.

67

Up to now, most analytical studies for annatto concerned with dairy products and high fat foods where annatto has well-established usage, such as cheese and dairy spreads (Scotter et al., 2002). Very few studies have documented the possibility to detect annatto or bixin and norbixin in meat tissue. For the determination of annatto, and more in particular bixin and norbixin, several detection techniques, such as ultraviolet (UV), photo-diode array (PDA) and ion trap mass spectrometry (MS) in combination 73 with liquid chromatography (LC) were evaluated. Within this perspective, our study aimed at 74 developing a routine residue method for the detection of annatto (bixin and norbixin) in meat using 75 liquid chromatography. Additionally, this method was validated in accordance with the Commission 76 Decision 2002/657/EC.

\section{Experimental}

\section{Chemicals}

80 Acetonitrile $(\mathrm{AcN})$, ethanol (EtOH) and acetic acid were of HPLC grade and supplied by VWR 81 (Merck, Darmstadt, Germany). HPLC grade Water was obtained from Across Organics (Fairlawn, NI, 82 USA). 
Standards

Bixin and norbixin powders were provided by LGC Promochem (Molsheim, France) with a purity of

$88.5 \%$ and $97.1 \%$ respectively. Annatto was purchased from Chromadex, Inc (Daimler St., Santa

Ana, CA, USA) and had a norbixin content of $14-16 \%$. Stock standard solutions of $200 \mathrm{ng} \mu \mathrm{l}^{-1}$ were

prepared in EtOH. Individual and composite working standards were prepared by appropriate dilution

of the standard stock solutions in $0.1 \%$ acetic acid in $\mathrm{AcN} / \mathrm{H}_{2} \mathrm{O}(80: 20)$. According to the instructions

of the supplier all standard and working solutions were stored in the dark at $-20{ }^{\circ} \mathrm{C}$ to minimize degradation and isomerization.

Extraction and clean-up

94 Extraction of $1 \mathrm{~g}$ homogenized meat tissue was extracted with $2 \mathrm{ml}$ acetonitrile (AcN). For validation $\mathrm{ml} \mathrm{min}{ }^{-1}$. vortex mixing and centrifugation $\left(5 \mathrm{~min}\right.$ at $5500 \mathrm{rpm}, 4{ }^{\circ} \mathrm{C}, 3726 \mathrm{~g}$ ) (Sorvall $\mathrm{RC} 5 \mathrm{C}$ plus, Goffin Meyvis, Belgium) $120 \mu \mathrm{l}$ of the supernatant with addition of $30 \mu 10.1 \%$ aqueous acetic acid was used for chromatographic analysis. For this, $60 \mu \mathrm{l}$ was injected.

\section{Chromatographic instrumentation}

Analysis was carried out using a High Performance Liquid Chromatography (HPLC) apparatus comprised of an 1100 series quaternary gradient pump and autosampler (Hewlett Packard, Palo Alto, CA, USA). Chromatographic separation was achieved using a Symmetry ${ }^{\mathrm{TM}} \mathrm{C}_{18}$ column $(5 \mu \mathrm{m}$ particle size, $150 \times 2.1 \mathrm{~mm}$, Waters, Milford, USA). The mobile phase consisted of a mixture of acetonitrile (A) and $0.1 \%$ aqueous formic acid (B). A linear gradient was run: $80 \% \mathrm{~A}: 20 \% \mathrm{~B}$, increasing to $95 \%$ A:5 \% B over $10 \mathrm{~min}$, increasing to $100 \%$ A over $5 \mathrm{~min}$ (hold $5 \mathrm{~min}$ ) and finally back to initial conditions $80 \%$ A:20\% B (hold 10 min). Total run time is 30 minutes at a mobile phase flow of 0.3 
110 When detection was performed using photodiode-array detection, a TSP Spectra System UV6000 LP

111 (Thermofinnigan, San José, CA, USA) with deuterium lamp was used with a detection range between 112300 and $580 \mathrm{~nm}$ (bandwidth $1 \mathrm{~nm}$ ). Additionally, two fixed wavelengths, 458 and $486 \mathrm{~nm}$ (bandwidth $1139 \mathrm{~nm})$, were tested.

115 Mass spectrometric (MS) detection was carried out with a Thermofinnigan LCQ DECA ion trap with 116 electrospray ionisation (ESI) interface using the above described chromatographic parameters.

117 Multiple mass spectrometry (MS ${ }^{2}$ ) spectra were acquired. The MS method consisted of segments, the 118 first (0-4 min) in negative ionisation mode, with a full scan MS scan event and an MS² scan event 119 (parent ion $379 \mathrm{MW}$, collision energy 25). The second segment (4-10 min), in positive ionisation 120 mode, consisted also of a full scan MS scan event and an $\mathrm{MS}^{2}$ scan event (parent ion 395 MW, 121 collision energy 30). Isolation width was set at 2.0 and activation Q at 0.250 .

122

123 Data analysis

124 Chromatograms and spectra were recorded and processed using Xcalibur 1.2. software 125 (Thermofinnigan, San José, CA, USA). All data were further analyzed using Microsoft ${ }^{\circledR}$ Excel 126 (Microsoft Corporation, USA).

\section{Quality assurance}

129 Before and after sample analysis, a standard mixture (10 ng on column) of the targeted colour agents 130 was injected to check the operation conditions of the LC-PDA devices. For quantitative analysis, 131 calibration standards were spiked at 3 levels in sample matrix $0.5,1$ and $5 \mathrm{mg} \mathrm{kg}^{-1}$. When using this 132 analytical method for routine analysis, quality control of the method was carried out by analysis of 133 blank and spiked comparable sample matrices together with every series of samples. At regular times, 134 secondary quality control, using blind fortified samples, was carried out within the routine analysis. 135

136 Validation procedure 
137 Method validation for the detection of annatto, bixin and norbixin in meat tissue was carried out 138 according to Commission Decision 2002/657/EC concerning detection of residues of veterinary drug 139 substances in matrices of animal origin. The examined validation parameters for the complete 140 analytical method were selectivity/specificity, linearity, precision, trueness/recovery, 141 applicability/ruggedness/stability and decision limit (CC $\alpha)$ and detection (CC $\beta)$ capability.

142 For this, blank sausage meat samples were fortified with a standard solution of a mixture of the dyes at 143 the level of $0.5,0.75,1,2$ and $4 \mathrm{mg} \mathrm{kg}^{-1}$ unless otherwise mentioned.

\section{Results and Discussion}

\section{Method performance}

147 Up to now, analytical approaches for the detection of annatto, or bixin and norbixin, are described for 148 different matrices, however, not for meat. Within this perspective, the aim of this study was to develop 149 an analytical approach for the detection of annatto, and more in particular bixin and norbixin in meat 150 tissue. The possibilities of 2 detection techniques, photodiode array (PDA) and ion trap mass 151 spectrometry (MS) were evaluated.

153 With the developed method, the two compounds of annatto, norbixin and bixin, were separated and 154 simultaneously detected by liquid chromatography (LC) using either photodiode array or ion trap mass 155 spectrometry with electrospray ionisation (ESI). Using PDA detection, the main peaks obtained from 156 the chromatographic separation of bixin and norbixin were scanned between 300 and $580 \mathrm{~nm}$ and were 157 similar to those reported by Scotter (1995). More in particular, 2 fixed wavelengths were used, 458 158 and $468 \mathrm{~nm}$. In figure 2, UV and $\mathrm{MS}^{2}$ chromatograms and spectra of $10 \mathrm{ng}$ bixin, norbixin and annatto 159 on column are shown. As can be noticed, the PDA-spectra of norbixin and bixin are identical with 160 absorption maxima on 458 and $486 \mathrm{~nm}$. Moreover, a typical increase in absorption intensity was 161 observed around $430 \mathrm{~nm}$ for both compounds. It was also observed that annatto mainly consists of 162 norbixin, though both $\alpha$ - and $\beta$-isomers of bixin and norbixin were present, consistent with Lancaster 163 and Lawrence (1996) (See figure 2). 
164 Multiple mass spectrometry $\left(\mathrm{MS}^{2}\right)$ was used to obtain structural information on the compounds 165 corresponding to each chromatographic peak. Bixin and norbixin produced the $[\mathrm{M}-\mathrm{H}]^{+}$ion in full scan 166 MS. This molecular ion, more in specific with m/z 379 and 395 for norbixin and bixin respectively, 167 was used as precursor ion for $\mathrm{MS}^{2}$. As can be seen in figure 2, the $\mathrm{MS}^{2}$ product ions of norbixin 168 (@379) are 253, 291, 310 and 335 whereas the main product ions of bixin (@ 395) are 317, 335, 345, 169363 and 377. Using MS² , detection is possible from a concentration level of $1 \mathrm{mg} \mathrm{kg}^{-1}$ as the presence 170 of several ions in the spectrum of bixin makes a clear interpretation difficult concerning matrix 171 interferences. With PDA the limit of quantification is $0.5 \mathrm{mg} \mathrm{kg}^{-1}$. Therefore, PDA detection was 172 preferred for use in routine analysis.

173

$174 \quad$ Full in-house method validation for bixin and norbixin in meat

175 Identification

176 For method validation and interpretation of the obtained results, criteria as described in the 177 Commission Decision 2002/657/EC were used. Targeted dye compounds in meat samples were 178 identified based on comparison of their relative retention time $( \pm 2.5 \%)$, which is the ratio of the 179 retention time of the analyte to that of the internal standard with a standard or fortified sample. When 180 detection was carried out with PDA, the absorption maxima $( \pm 2 \mathrm{~nm})$ in the spectrum of the analyte 181 were taken into account. Using mass spectrometric detection the ion ratio of the precursor/product ions 182 in the obtained spectrum was used when the corresponding peak in the chromatogram had a signal-to183 noise ratio of at least 3:1. In samples, the presence of bixin, norbixin and annatto was confirmed if the 184 retention time, the maximum absorption wavelength and the shape of the UV spectrum of the 185 unknown are in accordance with a fortified sample or a standard mixture. Comparison of the UV 186 spectra of a blank sample fortified at the level of $10 \mathrm{mg} \mathrm{kg}^{-1}$ for norbixin/bixin and at the level of 67 $187 \mathrm{mg} \mathrm{kg}^{-1}$ for annatto $\left(=10 \mathrm{mg} \mathrm{kg}^{-1}\right.$ norbixin) is shown in figure 3.

189 Specificity/selectivity

190 One of the general requirements of EC/2002/657, namely the investigation of interferences of matrix 191 components, specificity/selectivity was evaluated through the analysis of blank samples fortified 
192 separately with the considered compounds at national action level (AL). This AL was based on the 193 acceptable daily intake (ADI) for bixin and norbixin and a concentration level of $0.5 \mathrm{mg} \mathrm{kg}^{-1}$ has been 194 postulated. The specificity of the chromatographic method was proved since no significant interfering 195 peaks with a signal to noise ratio of 3 or more were observed at the retention times of the targeted 196 compounds by analysis of fortified samples. As described before, selectivity was proved since 197 conform 2002/657/EC, analytes are identified on the basis of their relative retention time and the ion 198 ratio of the precursor and product ions in the obtained spectrum.

\section{Linearity}

201 The linearity of the method was evaluated using repeated analysis of 5 calibration points in the 202 concentration range of $0.5,0.75,1,2$ and $4 \mathrm{mg} \mathrm{kg}^{-1}$. Correlation coefficients were between 0.93 and 1 .

\section{Trueness/precision}

205 Because no Certified Reference Material (CRM) was available, trueness of the measurements was 206 assessed by determining the recovery of additions of known amounts of the analytes to blank matrix. 207 For this purpose, blank meat tissue was fortified with $0.5,0.75,1,2$ and $4 \mathrm{mg} \mathrm{kg}^{-1}$ in 6 replicates and 208 on 3 different days. All calculated recoveries fulfilled the criterion that recovery should be between 80 209 and $110 \%$ for a mass fraction of, or greater than, $10 \mu \mathrm{g} \mathrm{kg}^{-1}$, except for norbixin at the level of $2 \mathrm{mg}$ $210 \mathrm{~kg}^{-1}$. The recoveries at this concentration level appeared to be higher for both compounds although 211 there was no specific explanation. To evaluate the precision of the method, repeatability and within212 laboratory reproducibility were determined. Repeatability was evaluated by calculating the 213 coefficients of variation (CV) using the data of 2 series of 3 replicates of fortified samples of an

214 identical matrix at 0.5 up to $4 \mathrm{mg} \mathrm{kg}^{-1}$. These analyses were carried out on two different occasions by 215 the same analyst and under repeatable conditions. According to the Horwitz (HW) equation, the CV 216 for the repeated analysis of fortified samples at a mass fraction of 0.5 and $4 \mathrm{mg} \mathrm{kg}^{-1}$ should not exceed $21718 \%$ and $13 \%$ respectively. All calculated CV values for norbixin and bixin were between 3 and $9 \%$. 
220 Because no proficiency tests were available for annatto, and more specific for norbixin or bixin, in 221 matrices of animal origin, to evaluate the reproducibility only the within-reproducibility was 222 considered. To this end, 3 series of 5 replicates of fortified samples at 0.5 up to $4 \mathrm{mg} \mathrm{kg}^{-1}$ were 223 analysed by different operators and on different days. The calculated CVs for both different operators, 224 different days of analysis and different concentrations were all between 3 and $17 \%$ for both 225 compounds considered. These values are of the same order of magnitude in comparison with the CVs 226 calculated using the Horwitz equation.

\section{$228 \quad$ Ruggedness}

229 In order to determine the ruggedness of the analytical method, experiments were carried out by 230 changing factors of the sample pre-treatment and clean-up like different SPE sorbents, extraction 231 solvents and volumes. In addition, a lot of parameters of the chromatographic analysis, e.g. injection 232 volume, liquid phases, chromatographic columns and solvent gradient programs were tested. For the 233 PDA and $\mathrm{MS}^{2}$ analysis different ionization modes and wavelengths were tested respectively. The 234 evaluation of the ruggedness of our method resulted in restraining the parameters as described in the 235 Materials and Methods section. Above this, a wide range of commercial processed pork meat products 236 (e.g. sausages, non-smoked gammon, smoked gammon and sliced cold meat products) were analysed 237 using the above described method. In all investigated matrices it was possible to determine annatto, 238 and more specifically norbixin and bixin at $0.5 \mathrm{mg} \mathrm{kg}^{-1}$ using PDA and $1 \mathrm{mg} \mathrm{kg}^{-1}$ using MS by 239 spiking into the matrix (see also figure 4). No problems were encountered with co-extractive 240 interferences, thus demonstrating the robustness of the method with respect to the analysis of 241 processed meat products.

243 Decision limit $(C C \alpha)$ and detection capability $(C C \beta)$

244 Finally, also the decision limit, which is the concentration level at and above which the sample is non245 compliant with $95 \%$ certainty, was calculated for the considered coloring agents. This value was 246 defined as the mean concentration of the spiked blank samples at AL concentration level plus 1.64 247 times the corresponding standard deviation at this concentration. The detection capability, which is the 
248 smallest concentration that can be detected with $95 \%$ certainty, was calculated as the CC $\alpha$ plus 1.64 249 times the above mentioned standard deviation. The $\mathrm{CC} \alpha$ values for norbixin and bixin were $0.6 \mathrm{mg} \mathrm{kg}^{-}$

$250{ }^{1}$ whereas calculation of the CC $\beta$ values for these compounds gave $0.7 \mathrm{mg} \mathrm{kg}^{-1}$.

In routine analysis, quantification of the obtained residues of norbixin and bixin was based on 253 calibration curves of 3 spikes $\left(0.5,1\right.$ and $\left.5 \mathrm{mg} \mathrm{kg}^{-1}\right)$ in the same matrix of the sample to compensate 254 for matrix effects.

\section{Conclusion}

257 In this study, a routine quantitative approach for the determination of annatto or norbixin and bixin in 258 meat tissue in the low $\mathrm{mg} \mathrm{kg}^{-1}$ concentration range is described. Using this validated method, the dye 259 annatto, and more in particular its compounds bixin and norbixin, can be detected in meat tissue from 260 the concentration level of $0.5 \mathrm{mg} \mathrm{kg}^{-1}$, which fits into the objectives of the inspection services. The 261 developed method has an excellent recovery and a good precision. The use of both photodiode array 262 and MS showed a large flexibility for the screening and confirmation of norbixin and bixin in routine 263 residue analysis.

265 Acknowledgements

266 The authors are grateful to Mieke Naessens and Els Laverge for assistance in the experimental work 267 and the skillful operation of the chromatographic devices.

\section{References}

270

271 2002/657/EC. 2002. Commission decision implementing council directive 96/23/EC concerning the 272 performance of analytical methods and the interpretation of results. Official Journal of the European 273 Communities L221: 8-36. 
275 Bittencourt C, Felicissimo MP, Pireaux JJ and Houssiau L. 2005. Study of annatto from Bixa Orellana 276 seeds: an application of time-of-flight secondary ion mass spectrometry. Spectroscopy Europe 17: 16$277 \quad 22$

278

279 EC/94/36. 1994. European Parliament and council directive on colours for use in foodstuffs. Official 280 Journal of the European Communities L 237: 13-29.

281

282 Engelberth-Holm J, Iversen S. 1955. Is the vegetable annatto butter colour cancerogenic? 283 Acta Pathologica, Microbiologica et Immunologica Scandinavica 37: 483-492.

284

285 Gloria MBA, Vale SR, Bobbio PA. 1995. Effect of water activity on the stability of bixin in 286 an annatto extract-microcrystalline cellulose model system. Food Chemistry 52: 389-391.

287

288 Hallagan JB, Allen DC, Borelleca JF. 1995. The safety and regulatory status of food, drug and 289 cosmetics colour additives exempt from certification. Food and Chemical Toxicity 33: 515290528.

291 Lancaster FE and Lawrence JF. 1996. High performance liquid chromatographic separation of 292 carminic acid, $\alpha$-bixin and $\beta$-bixin, and $\alpha$-norbixin and $\beta$-norbixin, and the determination of carminic 293 acid in foods. Journal of Chromatography A 732: 394-398.

294 Najar SV, Bobbio FO, Bobbio PA. 1988. Effects of light, air, anti-oxidants and pro-oxidants on 295 annatto extracts (Bixa orellana). Food Chemistry 29: 283-289.

296 Scotter MJ. 1995. Characterization of the colored thermal degradation products of bixin from annatto 297 and a revised mechanism for their formation. Food Chemistry 53: 177-185. 
298 Scotter MJ, Wilson LA, Appleton GP, Castle L. 2000. Analysis of Annatto (Bixa Orellana) Food 299 Coloring Formulations. 2. Determination of Aromatic Hydrocarbon Thermal Degradation Products by 300 Gas Chromatography. Journal of Agricultural and Food Chemistry 48: 484-488.

301 Scotter MJ, Thorpe SA, Reynolds SL, Wilson LA and Strutt PR. 1994. Characterization of the 302 principal coloring components of annatto using high performance liquid chromatography with 303 photodiode-array detection. Food Additives and Contaminants 11: 301-315.

305 Sotter MJ, Castle L, Honeybone A, Nelson C. 2002. Method development and analysis of retail foods 306 for annatto food colouring material. Food Additives and Contaminants 19: 205-222.

308 Tennant DR and O'Callaghan M. 2005. Survey of usage and estimated intakes of annatto extracts. 309 Food Research International 38: 911-917.

310

311 Van Esch GH, Van Genderen H., Vink HH. 1959. Über die chronische vertraglichkeit von 312 Annattofarbstoff. Zeitschrift für Lebensmitteleuntersuchung and forschung 111: 93-108.

313 Verger P. 1996. One example of utilization of the 'French approach'. Food Additives and 314 Contaminants 4: 417-419.

316 WHO. 2007. Safety Evaluation of certain food additives and contaminants. Online available:

317 whqlibdoc.who.int/trs/WHO_TRS_922.pdf 
<smiles>COC(=O)/C=C/C(C)=C/C=C/C(C)=C/C=C/C=C(C)/C=C/C=C(C)/C=C/C(=O)O</smiles>

A

Figure 1. Chemical structure of bixin (MW 395) (A) and norbixin (MW 378) (B) 


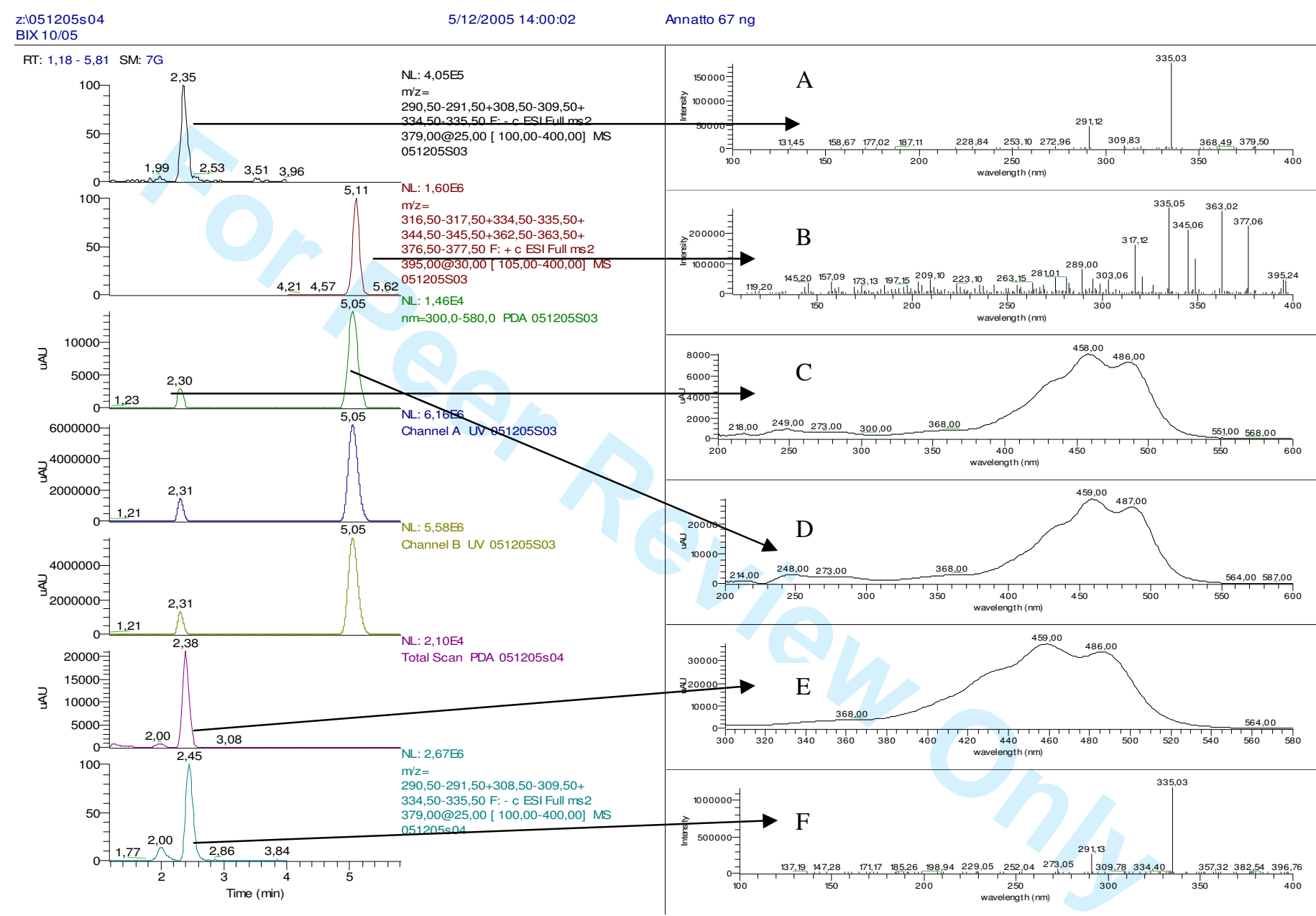

2 Figure 2. Chromatograms and $\mathrm{MS}^{2}$ spectra of norbixin (A) and bixin (B), PDA spectrum of norbixin (C) and bixin (D), PDA spectrum

3 of annatto (E) and $\mathrm{MS}^{2}$ spectrum of annatto (norbixin) (F) 


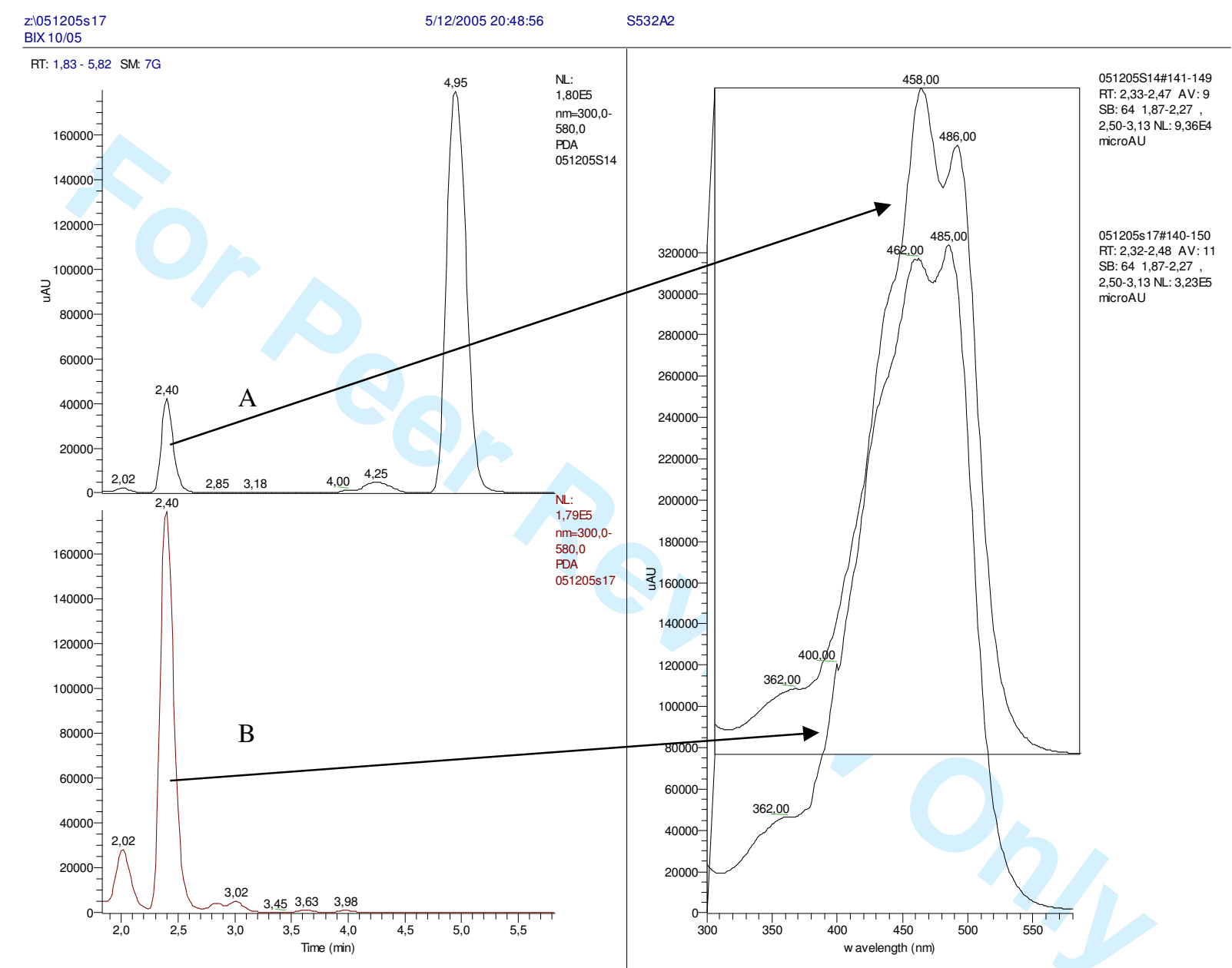

2 Figure 3. Comparison of the PDA spectra of norbixin and bixin (fortified sample at $10 \mathrm{mg} \mathrm{kg}^{-1}$ ) (A) and of annatto (fortified sample at $\left.367 \mathrm{mg} \mathrm{kg}^{-1}\right)(\mathrm{B})$. 


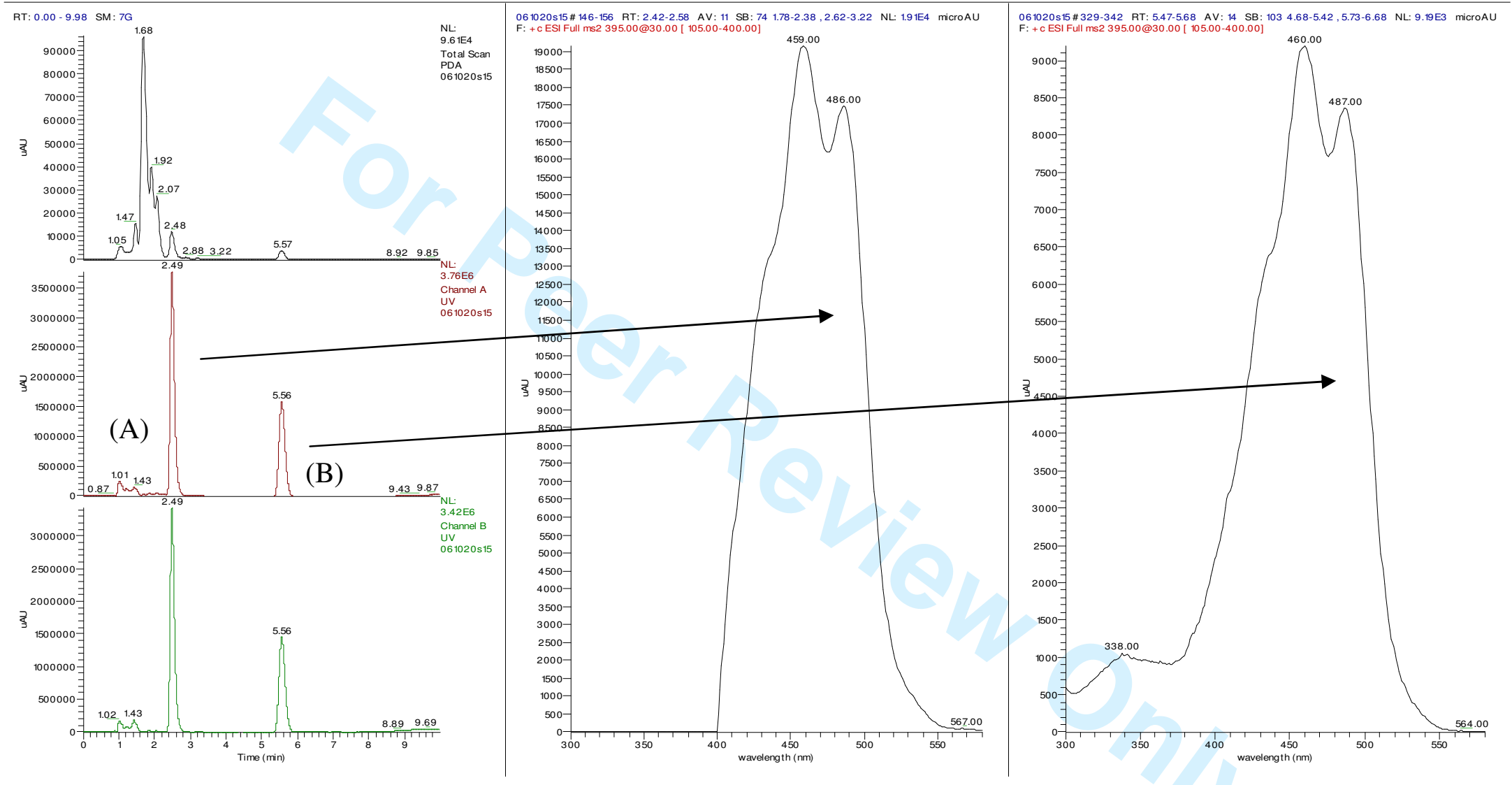

2 Figure 4. Chromatograms and PDA spectra of $1 \mathrm{~g}$ commercial pork sausage fortified with $0.5 \mathrm{mg} \mathrm{kg}^{-1}$ norbixin (A) and bixin (B). 